\title{
HUTANG PIUTANG DALAM TRANSAKSI TAWARRUQ DITINJAU DARI PERSPEKTIF AL-QUR'AN SURAT AL-BAQARAH AYAT 282
}

\section{ACCOUNTSPAYABLEINTRANSACTIONSTAWARRUQVIEWED FROM THEPERSPECTIVEAL-QURAN VERSESSURAH AL-BAQARAH282 Taufik $^{1 a}$ Sofian Muhlisin ${ }^{2}$}

\author{
1Program Studi Ekonomi Islam Fakultas Ekonomi Islam Universitas Djuanda, Jl. Tol Ciawi \\ No. 1, Kotak Pos 35 Bogor 16770. \\ ${ }^{2}$ Program Studi Ekonomi Islam Fakultas Ekonomi Islam Universitas Djuanda, Jl. Tol Ciawi \\ No. 1, Kotak Pos 35 Bogor 16770.
}

\begin{abstract}
At-Tawarruq is a form of sale and purchase agreement involving three parties, when the owner of the goods to sell goods to the first buyer at a price and payment delay, and then the first buyer to sell the goods to the ultimate purchaser. Price delay higher than the cash price, so the first buyer as borrowing money to delay payment. The aim this study is to know how Tawarruq transaction law payable in terms of interpretation Qur'an Surat al-Baqarah verse 282. The method used in this study is diskriptifkualitatif and literature, the data used in this study are primary data and secondary data. Primary data is data to be retrieved from the Quran Surat al-Baqarah, verse 282. Secondary data is the data source of additional data, consisting of al Hadith, documents, journals, magazines, books, internet and some other literature that has to do with research which is conducted. The result from this research is Legal payable in Tawarruq transaction of the first to the second party lawful for the contract and the terms of sale and purchase of the loan is clear and is willingness, for the sake of seeking the pleasure of Allah.
\end{abstract}

\begin{abstract}
ABSTRAK
At-tawarruq adalah bentuk akad jual beli yang melibatkan tiga pihak, ketika pemilik barang menjual barangnya kepada pembeli pertama dengan harga dan pembayaran tunda, dan kemudian pembeli pertama menjual barang tersebut kepada pembeli akhir. Harga tunda lebih tinggi dari harga tunai, sehingga pembeli pertama seperti mendapatkan pinjaman uang dengan pembayaran tunda. Tujuan penelitian ini adalah untuk mengetahui bagaimana hukum hutang piutang dalam transaksi tawarruq ditinjau dari tafsir al Qur'an surat al-Baqarah ayat 282.Metode yang di gunakan dalam penelitian ini adalah diskriptifkualitatif dan studi pustaka, data yang digunakan dalam penelitian ini adalah data primer dan data sekunder. Data primer ialah data yang akan diambil dari al Quran surat alBaqarah ayat 282. Data Sekunder ialah data sumber data tambahan, terdiri dari al Hadits, dokumen-dokumen, jurnal, majalah, buku, internet dan beberapa literatur lainnya yang ada hubungannya dengan penelitian yang dilakukan. Hasil penelitian menunjukkan hukum hutang piutang dalam transaksi tawarruq dari pihak pertama kepada pihak kedua halal selama akad dan syarat-syarat jual beli secara kredit tersebut jelas dan dilakukan secara kerelaan, demi mencari keridhaan Allah.
\end{abstract}

Taufik. 2013. Hutang Piutang Dalam Transaksi Tawarruq Di Tinjau Dalam Perspektif AlQur'an Surat Al-Baqarah ayat 282. Jurnal Syarikah1(1): 37 -47. 


\section{PENDAHULUAN}

Qardh

merupakan

utang

kebajikan/lunak tanpa imbalan, biasanya untuk pembelian barang-barang yang dapat diperkirakan dan diganti sesuai berat, ukuran dan jumlahnya.Satu-satunya akad berbentuk pinjaman yang diterapkan dalam perbankan syariah adalah Qardh dan Qardhul Hasan.Karena bunga dilarang dalam Islam, maka pinjaman Qardh atau Qardhul Hasan merupakan pinjaman tanpa bunga. Lebih khusus lagi, pinjaman Qardhul Hasan merupakan pinjaman kebijakan yang tidak bersifat komersial, tetapi bersifat social (Ascarya : 2008).

Pinjaman qardh biasanya diberikan oleh Bank kepada nasabahnya sebagai fasilitas pinjaman talangan pada saat nasabah mengalami over draft.Fasilitas ini dapat merupakan bagian dari satu paket pembayaran lain untuk memudahkan nasabah bertransaksi (Ascarya : 2008).Pihak yang berpiutang hendaknya berniat memberikan pertolongan kepada pihak yang berhutang, bila yang meminjam belum mampu mengembalikan, maka pihak yang memberikan hutang hendaknya memberikan waktu penundaan untuk membayarnya, Dan apabila yang meminjam betul-betul tidak mampu mengembalikan maka hendaknya orang yang memberi hutang membebaskannya (Abdul Rahman Ghazaly dkk).Sebagaimana Allah SWT berfirman dalam al Qur'an Surat An Nisa' ayat 58 .

Adapun hadist yang meriwayatkan tentang disunahkannya memberikan hutang yaitu (Muhammad bin Isma'il Abu 'Abdillah al-Bukhari al-Ja'fi) yaitu "Telah menceritakan kepada kami 'Abdul 'Aziz bin 'Abdullah Al Uwaisiy telah menceritakan kepada kami Sulaiman bin Bilal dari Tsaur bin Zaid dari Abu Al Goits dari Abu Hurairah radliallahu 'anhu dari Nabi shallallahu 'alaihi wasallam bersabda: "Siapa yang mengambil harta manusia (berhutang) disertai maksud akan membayarnya maka Allah akan membayarkannya untuknya, sebaliknya siapa yang mengambilnya dengan maksud merusaknya (merugikannya) maka Allah akan merusak orang itu". (Hadist Riwayat Bukhari).

Meskipun kita mengetahui hutang piutang diperbolehkan tapi Islam menyuruh umatnya agar menghindari hutang semaksimal mungkin, jika ia mampu membeli dengan tunai atau tidak dalam kesempitan ekonomi. Karena hutang akan selalu menjadi beban berat dan membahayakan akhlaq. Rasulullah saw. Pernah menolak menshalati jenazah seseorang yang diketahui masih meninggalkan beban hutang bagi keluarganya dan tidak ada harta untuk membayar hutang-hutang tersebut. Namun demikian, kebutuhan ekonomi manusia kadangkala tidak dapat terpenuhi dengan kegiatan hutang piutang mengingat terkadang manusia kesulitan untuk mendapatkan pinjaman demi memenuhi berbagai macam kebutuhan hidup. Memang Islam telah memberi jalan kepada manusia untuk memenuhi kebutuhan uang tunai dengan meminjam kepada orang berpunya dengan prinsip qardh (tanpa tambahan/bunga).Namun demikian. Masalah akan timbul ketika tidak ada orang yang bersedia memberikan pinjaman qardh, disatu pihak seseorang sangat membutuhkan uang tunai untuk menjalankan kegiatan ekonomi mereka baik untuk konsumsi maupun produksi.

Untuk mendapatkan uang tunai tanpa melakukan cara ribawi, beberapa pihak melakukan transaksi tawarruq. Namun demikian, transaksi tawarruq menjadi perdebatan oleh beberapa pihak mengenai kehalalannya.Sejumlah pihak berpandangan bahwa tawarruq sebagai sebuah kegiatan yang dibuat-buat sehingga unsur ribanya tidak tampak padahal esensinya adalah kegiatan ribawi. Dilain pihak tawarruq dianggap hal yang diperkenankan dalam Islam sebagai solusi untuk memenuhi kebutuhan uang tunai (Hendry Herijanto, Huscikceolah :2013).

Di dalam transaksi tawarruq terdapat hutang piutang didalamnya, sehingga transaksi ini memunculkan perdebatan 
yang sangat hebat di kalangan para ulamatentang halal atau haramkah transaksi tawarruq.

\section{MATERI DAN METODE}

Penelitian deskriptif kualitatif yaitu sebuah penelitian yang di maksudkan untuk mengungkap sebuah fakta empiris secara objektif ilmiah dengan berdasarkan pada logika keilmuan(Muhtar, 2013).Jenis penelitian yang di gunakan dalam penelitia ini adalah penelitian diskriptif kualitatif dan juga penulis menggunakan penelitian library research (studi pustaka).

Sumber data yang di gunakan penulis data yang bersifat kualitatif yaitu data Primer adalah data yang akan diambil langsung dari Al Qur'an. Dan data sekunder adalah data sumber data tambahan, terdiri dari al Hadits, dokumen-dokumen, jurnal, majalah, buku, internet dan beberapa literatur lainnya yang ada hubungannya dengan penelitian yang dilakukan.

Tehnik pengumpulan data dalam penelitian ini dilakukan dengan:

1. Kepustakaan.

2. Interview ( wawancara ).

Metode analisis untuk penelitian ini akan dianalisis dengan menggunakan Metode Content Analysis. Content Analysis merupakan analisis ilmiah tentang isi pesan suatu komunikasi. Secara teknis Content Analisis mencangkup upaya:

1. Klasifikasi tanda-tanda yang dipakai dalam komunikasi.

2. Menggunakan Kriteria sebagai dasar Klasifikasi.

3. Menggunakan teknik analisis tertentu sebagai pembuat prediksi.

Content Analysis menampilkan tiga syarat: Obyektivitas, pendekatan sistematis dan Generalisasi (Zaelani, 2007)

\section{HASIL DAN PEMBAHASAN}

\section{Teks Dan Terjemah Ayat}

Artinya: "Hai orang-orang yang beriman, apabila kamu bermu'amalah tidak secara tunai untuk waktu yang ditentukan, hendaklah kamu menuliskannya. dan hendaklah seorang penulis di antara kamu menuliskannya dengan benar. dan janganlah penulis enggan menuliskannya sebagaimana Allah mengajarkannya, maka hendaklah ia menulis, dan hendaklah orang yang berhutang itu mengimlakkan (apa yang akan ditulis itu), dan hendaklah ia bertakwa kepada Allah Tuhannya, dan janganlah ia mengurangi sedikitpun daripada hutangnya. jika yang berhutang itu orang yang lemah akalnya atau lemah (keadaannya) atau Dia sendiri tidak mampu mengimlakkan, Maka hendaklah walinya mengimlakkan dengan jujur. dan persaksikanlah dengan dua orang saksi dari orang-orang lelaki (di antaramu). jika tidak ada saksi dari dua orang laki-laki maka boleh satu laki-laki dan dua orang permpuan dari saksi-saksi yang kamu ridhai, supaya jika seorang lupa Maka yang seorang mengingatkannya. janganlah saksi-saksi itu enggan (memberi keterangan) apabila mereka dipanggil; dan janganlah kamu jemu menulis hutang itu, baik kecil maupun besar sampai batas waktu membayarnya. yang demikian itu, lebih adil di sisi Allah dan lebih menguatkan persaksian dan lebih dekat kepada tidak (menimbulkan) keraguanmu. (Tulislah mu'amalahmu itu), kecuali jika mu'amalah itu perdagangan tunai yang kamu jalankan di antara kamu, Maka tidak ada dosa bagi kamu, (jika) kamu tidak menulisnyadan persaksikanlah apabila kamu berjual beli; dan janganlah penulis dan saksi saling sulit menyulitkan. jika kamu lakukan (yang demikian), Maka Sesungguhnya hal itu adalah suatu kefasikan pada dirimu. dan bertakwalah kepada Allah; Allah mengajarmu; dan Allah Maha mengetahui segala sesuatu". (QS. AlBaqarah: 282)

\section{Asbab An-Nuzul}

Yang dimaksud dengan Asbab an-Nuzul adalah:

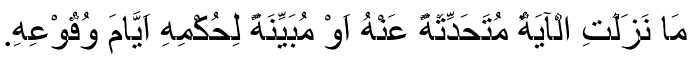
Sesuatu yang (karenanya) satu atau beberapa ayat turun membicarakannya atau menjelaskan hukumnya pada harihari terjadinya. 
Maksudnya, ia merupakan peristiwa yang terjadi pada masa Nabi saw atau pertanyaan yang diajukan kepada beliau, lalu turun satu atau beberapa ayat dari Allah SWT. Untuk menjelaskan sesuatu yang berkaitan dengan peristiwa itu, atau menjawab pertanyaan tersebut, baik peristiwa itu merupakan pertikaian yang berkembang (Al Zarqani, 2002).

Salah satu upaya untuk memahami al Qur`an dengan meninjau serta mempelajari asbab an-Nuzul (latar belakang) suatu ayat al Qur`an. Dengan pemahaman asbab anNuzul ini, maka seorang penafsir atau peneliti al Qur`an akan kebih professional dan konstektual dalam analisisnya.

Asbab an-Nuzul yang dapat penulis gambarkan mengenai surah al-Baqarah ayat 282 berdasarkan riwayat Dai Rabi' bahwa ayat ini diturunkan ketika seorang lelaki mencari saksi di kalangan orang banyak, untuk meminta persaksian mereka, tetapi tidak seorangpun yang bersedia.Maka diturunkanlah ayat ini (Sayis).

Ibnu Abbas berkata: Turunnya ayat ini berkenaan dengan transaksi bai' salamyang dilakukan oleh salah satu penduduk Madinah, kemudian ayat ini turun menjelaskan semua hal yang berkenaan dengan hutang piutang sekaligus (Wahbah Zuhaily). Maka dapat kita lihat bahwa ayat ini merupakan ayat terpanjang di dalam al Qur'an.

\section{Munasabah Ayat}

AlBaqarah ayat 282 ini adalah ayat terpanjang di dalam al Qur`an, dan yang dikenal oleh para ulama dengan ayat alMudayanah (ayat hutang piutang). Ayat ini ditempatkan setelah uraian tentang anjuraan bersedekah dan berinfak (ayat 271-274), kemudian disusul dengan larangan melakukan transaksi riba (ayat 275-279), serta anjuran memberi tangguhan kepada yang tidak mampu membayar hutangnya sampai mereka mampu atau bahkan menyedekahkan sebagian atau semua hutang itu (ayat 280) (HR. Daeng Najah).

Ayat ini merupakan lanjutan dari ayatayat yang menerangkan tentang keutamaan sedekah, menafkahkan harta di jalan Allah yang timbul dari hati sanubari, semata-mata karena Allah, dan dilandasi dengan rasa kasih sayang terhadap sesama manusia (Sayis,2011).

Selanjutnya, Allah melarang melakukan riba dan menerangkan keburukannya, karena riba itu semata-mata dilakukan untuk mencari keuntungan, tanpa mengindahkan kesulitan dan kesukaran orang lain. Pada ayat ini Allah menerangkan ketentuanketentuan dalam muamalah, yang didasarkan pada keadilan dan kerelaan masing-masing pihak, sehingga menghilangkan keraguraguan, buruk sangka dan sebagainya(Kementrian Agama RI : 2012).

\section{Tafsir Ayat}

Menurut Quraish Shihab dalam tafsirnya: Perintah ayat ini secara redaksional ditujukan kepada orang-orang beriman, tetapi yang dimaksud adalah mereka yang melakukan transaksi hutang piutang, bahkan secara lebih khusus adalah yang berhutang, ini agar yang memberi piutang merasa lebih tenang dengan adanya dua bukti,yaitu (1) Dari penulisan dan (2) dari Persaksian. Penulisan dan persaksiannya adalah perintah atau tuntutan yang sangat dianjurkan, walau kreditor tidak memintanya (Shihab:2009).

\section{Perintah Penulisan Transaksi Hutang Piutang/ Jual Beli}

Ibnu Katsir berkata: Allah SWT berfirman:

Artinya: Hendaklah kamu menulisnya. (QS. Al-Baqarah: 282)

Melalui ayat ini Allah memerintahkan adanya catatan untuk memperkuat dan memelihara.Perintah ini berobjek pada masalah-masalah rinci yang biasa terjadi di antara manusia. Maka orang-orang mukmin diperintahkan untuk mencatatnya, dengan perintah yang mengandung arti petunjuk, bukan perintah yang berarti wajib seperti yang dikatakan oleh sebagian ulama (AdDimasyqi : 2011).

Artinya: Penulis yang adil (QS. Al-Baqarah: 282) 
Menurut Wahbah Zuhaily, apabila orang-orang mukmin melakukan transaksi qard seperti jual beli barang dengan pembayaran kredit, atau jual beli salam, seperti jual beli barang dagangan yang ditangguhkan penyerahannya pada pembeli terhadap batas waktu tertentu, dengan menyebutkan jenis, ciri-ciri dan ukurannya, maka Allah memerintahkan agar menulisnya dengan menyebutkan hari, bulan, tahun pembayaran yang dijanjikan dengan sejelas jelasnya.

Menururt Imam Al-Maragi, setelah Allah mensyaratkan sifat adil untuk sang penulis, kemudian Allah mensyaratkan pula agar juru tulis mengetahui hukum-hukum fiqih dalam masalah penulisan hutang piutang. Sebab tulisan itu tidak bisa dijamin sempurna kecuali jika pelaksanaannya berdasarkan pengetahuan syariat dan syarat-syarat yang harus dipenuhi olehnya bedasarkan kebiasaan perundung undangan.

Artinya: Janganlah penulis menolak untuk menuliskannya sebagaimana Allah telah mngajarkan kepadanya. (QS. Al-Baqarah: 282)

Menurut Quraisy Shihab Penggalan ayat wala ya'ba ini, meletakkan tanggung jawab di atas pundak penulis yang mampu, bahkan setiap orang yang memiliki kemampuan untuk melaksanakan sesuatu sesuai dengan kemampuannya. Walaupun pesan ayat ini dinilai banyak ulama sebagai anjuran, ia menjadi wajib jika tidak ada selainnya yang mampu, dan pada saat yang sama, jika hak dikhawatirkan akan terabaikan.

Artinya: Hendaklah orang yang berhutang itu mendiktekan. (QS. Al-Baqarah: 282)

Menurut Wahbah Zuhaily, hendaknya orang yang berhutang mengimlakan yang sebenarnya pada penulis, tidak menambah dan tidak mengurangi tanggungan hutang yang sudah disepakati (Zuhaily:2001).

Artinya: Janganlah dia mengurangi sedikitpun daripadanya. (QS. Al-Baqarah: 282)

Imam Al-Maragi berkata: Mengenai larangan mengurangi hak, meskipun kecil, yang merupakan pengukuhan bagi ayat sebelumnya.

Artinya: Jika yang berhutang itu orang yang kurang akalnya atau lemah (keadaannya) (QS. Al-Baqarah: 282).

Imam Al-Maragi berkata: Apabila orang yang memberi hutang itu akalnya lemah, atau belumdewasa, pikun, bodoh, bisu atau gagu, maka orang yang menjadi walinya berhak menggantikan kedudukannya sebagai wakil. Jika ia seorang gagu, maka perlu diadakan seorang penerjemah yang bisa mengutarakan maksud sebenarnya tanpa mengurangi atau menambahi apa yang diinginkannya(Al-Maragi : 1993).

Artinya: dan janganlah kamu jemu menulis hutang itu, baik kecil maupun besar sampai batas waktu membayarnya. (QS. Al-Baqarah: 282)

Ibnu Katsir berkata: hal ini merupakan kesempunaan dari petunjuk, yaitu perintah untuk mencatat hak, baik yang kecil maupun yang besar. Karena disebutkan pada permulaannya la tas-amu, artinya janganlah kalian merasa enggan mencatat hak dalam jumlah seberapa pun, baik sedikit atupun banyak, sampai batas waktu pembayarannya (Al-Imam Abu Fida Isma'il Ibnu Kasir Ad-Dimasyqi).

Perintah diadakannya persaksian terhadap transaksi hutang piutang/jual beli.

Artinya: dan persasikanlah dengan dua orang saksi dari orang-orang lelaki ( di antaramu), jika tidak ada saksi dari dua oramg laki-laki maka boleh satu orang lelaki dan dua orang perempuan dari saksi saksi yang kamu ridhai. (QS. Al-Baqarah: 282)

Artinya: dan persaksikanlah jika kamu melakukan jual beli. (QS. Al-Baqarah: 282)

MenurutWahbah Zuhaily (2011), Allah juga menganjurkan agar diadakannya saksi dalam transaksi hutang piutang, dengan jumlah dua orang laki-laki, atau satu lakilaki dan dua orang wanita.

Menurut Imam As-Syafi'i, penerimaan kesaksian seorang saksi hendaklah dengan bersumpah. Beliau beralasan dengan sunnah Rasulullah Saw. Yang menyuruh saksi mengucapkan sumpah sebelum 
mengucapkan kesaksiannya. Sementara itu menurut Abu Hanifah, penerimaan kesaksian seseorang tidak perlu disertai dengan sumpah (HR. Daeng Najah: 2011).

Rahasia Diisyaratkan Seorang Lelaki Dan Dua Wanita Sebagai Saksi

Artinya: Maka satu lelaki dan dua wanita. (QS. Al-Baqarah: 282)

Imam Al-Maragi berkata: Karena dikhawatirkan salah satunya lupa atau salah, lantaran perhatiannya yang kurang terhadap masalah yang dihadapi, maka salah seorang dari mereka mengingatkan temannya. Dengan demikian kesaksian yang satu, melengkapi kesaksian lainnya.Di samping itu, bagi hakim, ketika menginterogasi salah seorang dari keduannya, mereka harus disaksikan oleh lainnya, dan dianggap cukup sebagian kesaksiaannya, dan sebagian lagi oleh sebagian lainnya, begitu seterusnya. Namun, banyak sekali kalangan qadi yang tidak mengetahui cara sebenarnya dalam melaksanakan yang seharusnya ia perbuat (Ahmad Musthafa Al-Maragi).

Quraisy Shihab berkata: Persoalan ini harus dilihat pada pandangan dasar Islam tentang tugas utama wanita dan fungsi utama yang dibebankan atasnya. Ingatan wanita dalam soal rumah tangga pastilah kuat daripada pria yang perhatiaannya lebih banyak tertuju pada kepada kerja, perniagaan, termasuk hutang piutang.Ingatannya juga pasti lebih kuat daripada wanita yang perhatiaan utamanya bukan tertuju kesana.Atas dasar besar kecilnya perhatian itulah tuntunan di atas ditetapkan.Ayat ini tidak berbicara kemampuan intelektual wanita, bukan berarti kemampuannya menghafal lebih rendah daripada lelaki. Kenyataan dalam masyarakat ikut membuktikan kekeliruan persepsi sebagian orang, ulama dan intelektual (Shihab :2009).

Adapun firman Allah yang berbunyi:

Artinya: Dan janganlah para saksi itu menolak apabila diminta (QS. Al-Baqarah: 282)
Ibnu katsir berkata: Makna ayat ini menurut suatu pendapat yaitu apabila para saksi itu dipanggil untuk mengemukakan kesaksiaannya, maka mereka harus mengemukakannya. Pendapat ini dikatakan oleh Qatadah dan Ar-Rabi' Ibnu Anas. Berdasrkan pengertian ini ditarik kesimpulan bahwa mengemukakan kesaksian itu hukumnya fardu kifayah, ini juga menurut jumhur ulama(Ad-Dimasyqi : 2011).

Artinya: dan persaksikanlah apabila kamu berjual beli (QS. Al-Baqarah: 282)

Ibnu katsir berkata: Buatlah persaksian atas hak kalian jika memakai tempo waktu, atau tidak memakai tempo waktu. Dengan kata lain buatlah persaksian atas hak kalian dalam keadaan apapun(Al-Imam Abu Fida Isma'il Ibnu Kasir Ad-Dimasyqi : 2011).

\section{Hubungan Antara Tawarruq Dengan} Ayat 282

Menurut Anas Al-Hifni Maksud dari ayat فاكثيُوٌْْ (maka tulislah transaksi hutang piutang itu) adalah orang yang melakukan transaksi hutang piutang atau tawarruq harus mengadakan pencatatan sedangkan

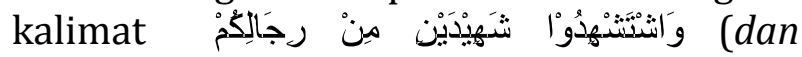
persaksikanlah jika kamu berjual beli) perintah persaksian ini juga ditujukan ke dalam transaksi tawarruq, yaitu dari pihak pertama ke pihak kedua dan ayat ini juga bisa masuk kepada pihak ketiga di dalam transaksi tawarruq.

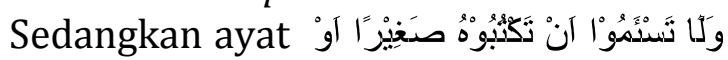
كَيِيًْا إلَّى آجلِلهِ (dan jangan kamu jemu menulis hutang itu, baik kecil maupun besar sampai batas waktu membayarnya) ini merupakan ayat kritikan terhadap orang yang melakukan transaksi hutang piutang atau tawarruq agar mereka mengadaan pencatatan.

Adapun Kalimat إلَا آنْ تَكَوْنَ تِجَارَةَ حَاضِيرَة (kecuali jika mu'amalah itu merupakan perdagangan tunai)maksudnya adalah, orang yang melakukan transaksi jual beli atau tawarruq dari pihak kedua pada pihak ketiga harus mencatatnya dan mempersaksikannya, kecuali transaksi tersebut tunai maka tidak harus mencatat dan mempersaksikannya. 


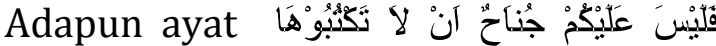
(maka tidak ada dosa bagimu, jika kamu tidak menulisnya) menurut beliau ayat ini erat kaitannya dengan transaksi tawarruq.Yaitu dari pihak pertama kepada pihak ke dua harus di catat dan di persaksikan, dari pihak kedua kepada pihak ketiga tidak harus dicatat karena merupakan penjualan secara tunai(Anas Alhifni : 2014).

\section{Hukum Hutang Piutang Dalam Transaksi Tawarruq Ditinjau Dari Tafsir Al Quran Surat Al-Baqarah Ayat 282}

Menurut Quraish Shihab: Adapun menjual barang dengan mencicil tidak terlarang, selama waktu dan jumlah cicilan jelas bagi penjual dan pembeli, walupun harganya lebih tinggi daripada harga jual kontan (M. Quraisy Shihab).

Seorang pembeli adakalanya membeli barang dagangan untuk dimanfaatkan sendiri dan adakalanya untuk dijual kembali.Kedua jenis jual beli seperti ini boleh menurut kesepakatan para ulama. Tetapi adakalanya juga seseorang melakukan jual beli hanya untuk mendapatkan keuntungan berupa dirham, maka perlu dilihat apakah harganya sama secara tunai. Seseorang yang membeli barang secara berjangka kemudian menjual kembali barang itu di pasar secara kontan dengan tujuan untuk mendapatkan tambahan pembayaran, jual beli seperti ini makruh menurut pendapat para ulama (AsSa'di :2008).Maka penulis menyimpulkan bahwa hutang piutang dalam transaksi tawarruq dari pihak pertama kepada pihak kedua, halal selama akad dan syarat-syarat jual beli secara kredit tersebut jelas dan dilakukan secara kerelaan, demi mencari keridhaan Allah. Waallahu A'lam Bisshawab.

\section{KESIMPULAN DANIMPLIKASI}

Dari pembahasan pada bab-bab yang lalu, dapat ditarik kesimpulan sebagai berikut:

1. Hutang Piutang Dalam Transaksi Tawarruq adalah hutang piutang terhadap suatu barang dalam transaksi jual beli dari pihak pertama (penjual) kepada pihak kedua (pembeli), kemudian pihak

2. kedua menjual barang tersebut kepada pihak ketiga selain pemberi hutang/penjual.

3. Hukumtawarruq berdasarkan kajian Islam terbagi menjadi dua pendapat:

a. Hukumnya Bolehjika pihak ketiga tidak ditentukan oleh pihak pertama.Ini adalah pendapat kebanyakan ulama hanafiyah dan hanabilah, imam syafi'i, Iyas bin Mu'awiyah, dan kebanyakan ulama di zaman ini.

b. Hukumnya haram karena menyerupai transaksi al-Inah.ini adalah pendapat Ibnu Taimiyah, Ibnu Qayyim karena perdagangan tersebut merupakan bai' mudhtharri. ini juga merupakan pendapat 'Umar bin 'Abdul 'Aziz serta dikuatkan oleh Syaikhul Islam Ibnu Taimiyah, Ibnul Qoyyim dan fatwa Al-Lajnah AdDa imah Saudi Arabia.

Adapun hukum menjual barang secara kredit, kemudian barang tersebut dijual lagi oleh konsumen kepada pihak lain dengan kontan dengan harga yang lebih tinggi, atau kita sebut tawarruq, setelah penulis teliti, dari beberapa tafsir yang telah dikemukakan sebelumnya, maka hukum hutang piutang dalam transaksi tawarruq dihalalkan selama memenuhi syarat-syarat yang sudah ditentukan.

\section{DAFTAR PUSTAKA}

Penulis Ascarya. 2011. Akad dan Produk Bank Syariah. Jakarta: PT. Grafindo Persada.

Al-Fauzan, Syekh Shalih, Al-Ustsaimen Shalih Syekh, Bazz Bin Aziz Abdul, Syekh, As-Sa'di Abdurrrahman. 2008. Fikih Jual Beli. Jakarta: senayan publishing.

Ad-Dimasyqi, Kasir, Ibnu Isa'il Fida Abu AlImam. 2011. Tafsir Ibnu Kasir. Juz 
3.terjemah. Bandung: Sinar Baru Algensindo.

Al-Maragi, Musthafa Ahmad. 1993. Tafsir AlMaragi, juz 3. terjemah. Semarang: PT. Karya Toha Putra.

Al-Ja'fi, Al-Bukhari 'Abdillah Abu Isma'il Bin Muhammad. 2008. Shahih AlBukhari. Dimaskus: Dar Thuwaqun Nahjah.

Al-Zarqani, Adzim Abdul Muhammad Syaekh, 2002.Manahil Al-'Urfan Fi 'Ulumul Quran, Jakarta: Gaya Media Pratama

Ghazaly, Rahman Abd dkk. 2010. Fiqih Muamalat. Jakarta: Kenacana Kenada Media Group.

Kementrian Agama RI. 2012. Al Quran dan Tafsirnya.jilid 1. Indonesia: PT. Sinerga Pustaka Indonesia.

Muhtar 2013. Metode Praktis Penelitian Deskriptif Kualitatif. Jakarta: Referensi Gp Press Grup.

Najah,Daeng Hr. 2011. Akad Bank Syariah. Yogyakarta: Pustaka Yestisia.

Shihab, Quraisy M. 2009. Tafsir alMishbah.Tangerang: Lentera Hati.

Sabiq, Sayyid Muhammad. 2009. Fiqih Sunnah. Jakarta Pusat: PT Pena Pundi Aksara. cet.1.

Sayis, Ali M, Tafsir Ayat Ahkam. Kairo: Universitas Syariah Islam.

Zuhaily, Wahbah. 2009. al-Tafsir al-Munir fi al-'Qidah wa as-Syari'ah wa alManhaj.jilid 3. Dimaskus: Darul Fikri

Sumber Internet

Herijanto,Hendry.Huscikceolah.Hukum Tawarruq Berdasarkan Kajian Fiqih Terpadu duscikceolah.wordpress.com.
Wasitho, Muhammad. Bahaya Hutang Piutang Menurut Pandangan Islam. Abu fawaz.wordpress.com 